\title{
Two phosphonium cation-based ionic liquids as lubricant additive to a polyalphaolefin base oil
}

\author{
R. González ${ }^{\mathrm{a}, c^{*}}$, J.L. Viesca ${ }^{\mathrm{b}, \mathrm{c}}$, A. Hernández Battez ${ }^{\mathrm{b}, \mathrm{c}}$, M. Hadfield ${ }^{\mathrm{c}}$ \\ A. Fernández-González ${ }^{\mathrm{d}}, \mathrm{M}$. Bartolomé ${ }^{\mathrm{a}}$ \\ ${ }^{\text {a }}$ Department of Marine Science and Technology, University of Oviedo, Asturias, Spain \\ ${ }^{\mathbf{b}}$ Department of Construction and Manufacturing Engineering, University of Oviedo, Asturias, Spain \\ ${ }^{\mathfrak{c}}$ Faculty of Science \& Technology, Bournemouth University, UK \\ ${ }^{\mathrm{d}}$ Department of Physical and Analytical Chemistry, University of Oviedo, Asturias, Spain \\ ${ }^{(*)}$ Email: gonzalezrruben@uniovi.es
}

\begin{abstract}
This paper studies the tribological performance of two phosphonium cation-based ionic liquids: trihexyltetradecylphosphonium bis(2,4,4-trimethylpentyl) phosphinate $\left(\left[\mathrm{P}_{6,6,6,14}\right]\left[(\mathrm{iC} 8)_{2} \mathrm{PO}_{2}\right]\right)$ and trihexyltetradecylphosphonium bis(2-ethylhexyl) phosphate $\left(\left[\mathrm{P}_{6,6,6,14}\right][\mathrm{BEHP}]\right)$, as lubricant additive at 1 $\mathrm{wt} \%$ to a polyalphaolefin. A comparison of their tribological behavior was made to that of one type of zinc dialkyldithiophosphate (ZDDP). Stribeck curve tests were made in a Mini Traction Machine (MTM) tribometer at entrainment speeds ranging from 2000 to $10 \mathrm{~mm} / \mathrm{s}, 30 \mathrm{~N}$-load, slide-to-roll ratio (SRR) of $50 \%$, and temperatures of $40,60,80$ and $100^{\circ} \mathrm{C}$. Tribofilm formation tests were also conducted in the MTM at $100{ }^{\circ} \mathrm{C}$, load of $50 \mathrm{~N}$, entrainment speed of $150 \mathrm{~mm} / \mathrm{s}$, SRR of $50 \%$, and duration of $60 \mathrm{~min}$. Additionally, reciprocating 60-min wear tests at $60 \mathrm{~N}-$ load, frequency of $15 \mathrm{~Hz}$, stroke length of $4 \mathrm{~mm}$ and temperature of ... were performed with IL-containing mixtures at 0.5 and $1 \mathrm{wt} \%$. Coefficient of friction was recorded during the tests, and wear on the discs surface was measured using confocal microscopy. SEM and EDS were also used for studying the lubricant-surface interactions after these tests. Lubricants including $\left[\mathrm{P}_{6,6,6,14}\right]\left[(\mathrm{iC} 8)_{2} \mathrm{PO}_{2}\right]$ exhibited better tribological performance than $\left[\mathrm{P}_{6,6,6,14}\right][\mathrm{BEHP}]$ ones and close to the ZDDP results. SEM images of worn surfaces exhibited evidence of plastic deformation and adhesive wear and EDS analysis showed that only active elements (P, S, Zn) were detected for mixtures containing ZDDP. XPS analysis indicated a different lubrication mechanism of the blends with ionic liquids compared with the ZDDP ones.
\end{abstract}

Keywords: phosphonium cation-based ionic liquids; additive; friction; wear; ZDDP

\section{Introduction}

Friction, wear and lubrication (tribology problems) continue being a major challenge for industry, especially in fields such as aerospace, electronics and computers, where a lot of efforts are still necessary for optimizing practical applications. Nowadays, lubrication is a key factor to achieve friction and wear reductions, and then contribute to decrease energy consumption and emissions, which are important benefits for society. In order to accomplish the goal of reducing friction and wear through lubrication, it is very important the use of specific additives in lubricant formulation.

Ionic liquids are a current research topic in lubrication as possible additive to be used in order to prevent direct metal/metal contacts and consequently damages on the surfaces [1-4]. One ionic liquid is a salt which melts below $100{ }^{\circ} \mathrm{C}[5]$ much of them are liquids at room temperature and then are called "room temperature 
ionic liquid" (RTIL) [6]. The first paper about the use of ionic liquids in lubrication was published in 2001 [7]. These substances have remarkable properties for lubrication such as large liquid range, low volatility and flammability and high thermal stability [3,8-12]. Despite of the fact that these substances have shown great performance as neat lubricants [13-24], their current relatively high cost is still a drawback. Therefore, the utilization of ILs as a lubricant additive should reduce the cost implications without losing the benefits of chemical interaction with surfaces, which can provoke friction and/or wear reductions [25].

On the other hand, the ionic character of these substances means that most of them are not capable of blending with neutral hydrocarbon oils (mineral oils and polyalphaolefins), which result in forming oil-IL emulsions with limited stability or mixtures with very low concentration of ionic liquid [24,26-30]. This inherent low solubility in non-polar substances leads to use the ionic liquids as additive in polar base oils (e.g. esters) [29,31-33]. However, phosphonium cation-based ionic liquids have shown excellent friction and wear reduction results when they were used as oil additive even in non-polar oils, showing also a good solubility $[19,29,42,34-41]$. The tribological improvement of using polar substances as additive in nonpolar oils was proved by some authors in the past [43-45] and that approach can be used again with ionic liquids.

Despite of the fact that some researches have been focused on the tribological behavior of phosphonium cation-based ionic liquids as lubricant additive in different material pairs, no works dealt with the effectiveness of using that cation combined with phospinate and phosphate anions as lubricant additive in a synthetic base oil for a steel-steel contact. This work deals with the use of the trihexyltetradecylphosphonium $\quad$ bis(2,4,4-trimethylpentyl) phosphinate $\left(\left[\mathrm{P}_{6,6,6,14}\right]\left[\left(\mathrm{iC}_{2}\right)_{2} \mathrm{PO}_{2}\right]\right)$ and trihexyltetradecylphosphonium bis(2-ethylhexyl) phosphate $\left(\left[\mathrm{P}_{6,6,6,14}\right][\mathrm{BEHP}]\right)$ ionic liquids as additive in a polyalphaolefin. Two blends of this base oil and ZDDP were used as comparison samples and in all cases the IL and ZDDP concentrations took into account different engine oil specifications (PC-11, ILSAC GF5 and ILSAC GF-6) that recommend a phosphorus concentration under 800 ppm [46].

\section{Experimental details}

\subsection{Ionic liquids and base oil}

The phosphonium cation-based ionic liquids: trihexyltetradecylphosphonium bis(2,4,4-trimethylpentyl) phosphinate $\left(\left[\mathrm{P}_{6,6,6,14}\right]\left[(\mathrm{iC} 8)_{2} \mathrm{PO}_{2}\right]\right)$ and trihexyltetradecylphosphonium bis(2-ethylhexyl) phosphate $\left(\left[\mathrm{P}_{6,6,6,14}\right][\mathrm{BEHP}]\right)$, were supplied by Io-Li-Tec (Ionic Liquid Technologies $\left.\mathrm{GmbH}\right)$ and used in this work 
as lubricant additive to a polyalphaolefin (PAO 4) provided by Repsol S.A. A traditional lubricant additive, like zinc dialkyldithiophosphate (ZDDP), was used for comparison purposes. Table 1 exhibits the properties of all these lubricant compounds. Description and chemical structure of the $\left[\mathrm{P}_{6,6,6,14}\right]\left[(\mathrm{iC} 8)_{2} \mathrm{PO}_{2}\right]$ and $\left[\mathrm{P}_{6,6,6,14}\right][\mathrm{BEHP}]$ ionic liquids are shown in Table 2.

Table 1 Properties of the lubricant samples.

\begin{tabular}{|c|c|c|c|c|}
\hline \multirow[t]{2}{*}{ Lubricant samples } & \multirow{2}{*}{$\begin{array}{c}\text { Density }\left(\mathbf{g} / \mathbf{c m}^{\mathbf{3}}\right) \\
\mathbf{a ~ 2 0}^{\circ} \mathbf{C} \\
\text { ASTM D } 4052\end{array}$} & \multicolumn{2}{|c|}{$\begin{array}{c}\text { Kinematic viscosity }\left(\mathbf{m m}^{2} / \mathbf{s}\right) \\
\text { ASTM D } 445\end{array}$} & \multirow[t]{2}{*}{$\begin{array}{l}\text { Viscosity Index } \\
\text { ASTM D } 2270\end{array}$} \\
\hline & & $40^{\circ} \mathrm{C}$ & $100^{\circ} \mathrm{C}$ & \\
\hline $\mathrm{PAO} 4$ & 0.815 & 16.89 & 3.89 & \\
\hline ZDDP & 1.200 & 658.66 & 14.47 & - \\
\hline$\left[\mathrm{P}_{6,6,6,14}\right]\left[(\mathrm{iC} 8)_{2} \mathrm{PO}_{2}\right]$ & 0.889 & 528.93 & 55.06 & 169 \\
\hline$\left[\mathrm{P}_{6,6,6,14}\right][\mathrm{BEHP}]$ & 0.915 & 528.05 & 59.00 & 181 \\
\hline
\end{tabular}

Table 2 Description and chemical structure of the $\left[\mathrm{P}_{6,6,6,14}\right]\left[(\mathrm{iC} 8)_{2} \mathrm{PO}_{2}\right]$ and $\left[\mathrm{P}_{6,6,6,14}\right][\mathrm{BEHP}]$.

\begin{tabular}{|c|c|c|c|c|}
\hline $\begin{array}{l}\text { IUPAC name } \\
\text { (CAS number) }\end{array}$ & $\begin{array}{l}\text { Empirical } \\
\text { formula }\end{array}$ & $\begin{array}{c}\text { Purity } \\
\text { (\%) }\end{array}$ & $\begin{array}{c}\text { Molecular } \\
\text { weight }\end{array}$ & Chemical structure \\
\hline $\begin{array}{l}\text { Trihexyltetradecylphosphoniun } \\
\text { bis(2,4,4-trimethylpentyl) } \\
\text { phosphinate } \\
(465527-59-7)\end{array}$ & $\mathrm{C}_{48} \mathrm{H}_{102} \mathrm{O}_{2} \mathrm{P}_{2}$ & 95 & 773.27 & \\
\hline $\begin{array}{l}\text { Trihexyltetradecylphosphoniun } \\
\text { bis(2-ethylhexyl)phosphate } \\
(1092655-30-5)\end{array}$ & $\mathrm{C}_{48} \mathrm{H}_{102} \mathrm{O}_{4} \mathrm{P}_{2}$ & 98 & 805.29 & \\
\hline
\end{tabular}

The corrosion character of the $\left[\mathrm{P}_{6,6,6,14}\right]\left[(\mathrm{iC} 8)_{2} \mathrm{PO}_{2}\right]$ and $\left[\mathrm{P}_{6,6,6,14}\right][\mathrm{BEHP}]$ ionic liquids was studied in a previous work [13]. No corrosion activity for both ionic liquids was detected on the surface of AISI 52100 steel discs after tests made at room temperature.

A Mettler Toledo TGA/SDTA851 thermogravimetric analyzer (TGA) was used in order to determine the decomposition temperatures of the ionic liquids and the base oil. Dynamic tests were made from room temperature to approximately $600{ }^{\circ} \mathrm{C}$ at $10^{\circ} \mathrm{C} / \mathrm{min}$ heating rate in both oxygen and nitrogen atmospheres with a flow rate of $50 \mathrm{~mL} / \mathrm{min}$. 
One of the key aspects in the use of ILs as additive in lubricants is their solubility in the base oil. The solubility of the $\left[\mathrm{P}_{6,6,6,14}\right]\left[(\mathrm{iC} 8)_{2} \mathrm{PO}_{2}\right]$ and $\left[\mathrm{P}_{6,6,6,14}\right][\mathrm{BEHP}]$ ionic liquids in PAO 4 was tested following a methodology similar to that used by Otero et al. [44]: a Labonet VX 100 Vortex was employed to mix $2 \mathrm{~mL}$ of base oil and $1 \mathrm{~mL}$ of IL in order to obtain a homogeneus suspension that guaranteed the saturation of the IL in the base oil. Later, a Thermo Scientific Heraeus Labofuge 200 centrifuge was employed to centrifuged the blend for five minutes at $5300 \mathrm{rpm}$. The densest phase was removed, and the base oil (the less dense phase) was analyzed by ICP-MS after being decanted and digested in a microwave oven (65\% HNO3: 25\% H2O2 7:1), diluting the residue as necessary. The results of the solubility tests showed an ionic liquid concentration in the base oil around 22 and $16 \mathrm{wt} \%$ for $\left[\mathrm{P}_{6,6,6,14}\right]\left[(\mathrm{iC} 8)_{2} \mathrm{PO}_{2}\right]$ and $\left[\mathrm{P}_{6,6,6,14}\right][\mathrm{BEHP}]$, respectively.

Taking into account the above solubility results, PAO4-IL mixtures containing 0.5 and $1 \mathrm{wt} \%$ of IL were prepared. These IL concentrations corresponded with a phosphorus concentration of 350 and 700 ppm for $\left[\mathrm{P}_{6,6,6,14}\right]\left[(\mathrm{iC} 8)_{2} \mathrm{PO}_{2}\right]$ and 358.5 and $717 \mathrm{ppm}$ for $\left[\mathrm{P}_{6,6,6,14}\right][\mathrm{BEHP}]$. PAO-ZDDP mixtures with concentrations of ZDDP of 0.4 and $0.8 \mathrm{wt} \%$ (corresponding to 351.5 and $703 \mathrm{ppm}$ of phosphorus) were also prepared to be used as reference lubricant samples.

Density and dynamic viscosity of the above samples at atmospheric pressure in a range of 20 to $100{ }^{\circ} \mathrm{C}$ were measured according to ASTM D7042 using a Stabinger SVM3001 viscometer.

\subsection{Tribological tests}

In order to study friction and tribofilm formation in a steel-steel contact, two different rolling-sliding tribological tests were carried out in a Mini Traction Machine tribometer with spacer layer image mapping (MTM2 3DSLIM -PCS Instruments-). In both cases, the pure PAO 4 and the PAO4-IL mixtures with the highest phosphorus concentration were tested using a configuration formed by a 19.05 mm-diameter AISI 52100 steel ball $(\mathrm{Ra} \approx 0.01 \mu \mathrm{m})$ and a $46 \mathrm{~mm}$-diameter AISI 52100 steel disc $(\mathrm{Ra} \approx 0.01 \mu \mathrm{m})$. The ball is loaded against the face of the disc and the ball and disc are driven independently to create a mixed rolling/sliding contact under the presence on $10 \mathrm{~mL}$ of lubricant.

Firstly, experiments for evaluating the lubricant behavior under different lubrication regimes (Stribeck curve) were performed. The test conditions used for these experiments were: $30 \mathrm{~N}$-load (corresponding to a maximum contact pressure of $0.95 \mathrm{GPa}$ ), slide-to-roll ratio (SRR) of 50\%, mean entrainment speeds ranging from 2000 to $10 \mathrm{~mm} / \mathrm{s}$ (steps of $100 \mathrm{~mm} / \mathrm{s}$ from 2000 to $100 \mathrm{~mm} / \mathrm{s}$, and steps of $10 \mathrm{~mm} / \mathrm{s}$ from 100 
to $10 \mathrm{~mm} / \mathrm{s}$ ), and temperatures of $40,60,80$ and $100{ }^{\circ} \mathrm{C}$ were developed. Traction coefficient and electrical contact resistance (ECR) between the ball and the disc were measured during tests.

Secondly, the thickness of the tribofilm formed on the ball surface during an specific test was measured with in situ spacer layer interferometry as described in [47]. Tests were conducted at a lubricant temperature of $100{ }^{\circ} \mathrm{C}$, load of $50 \mathrm{~N}$ (corresponding to a maximum contact pressure of $1.13 \mathrm{GPa}$ ), mean entrainment speed of $150 \mathrm{~mm} / \mathrm{s}$, SRR of $50 \%$, and duration of $60 \mathrm{~min}$.

Finally, accelerate wear tests were performed for all mixtures and the pure base oil using a Bruker UMT-3 tribometer with a reciprocating ball-on-plate configuration. As upper specimen (ball) were used AISI 52100 chrome steel balls with diameter of $6.0 \mathrm{~mm}(\mathrm{Ra} \leq 0.05 \mu \mathrm{m})$ and hardness of 58-66 HRC). On the other hand, as lower specimen (disk) were employed $3 \mathrm{~mm}$-thick and $10 \mathrm{~mm}$-diameter AISI 52100 steel disks $(\mathrm{Ra} \leq 0.02 \mu \mathrm{m})$ with hardness of $190-210 \mathrm{HV}_{30} .60$-min tests at a load of $60 \mathrm{~N}$ (corresponding to maximum contact pressure of $1.91 \mathrm{GPa}$ ), a frequency of $15 \mathrm{~Hz}$ and stroke length of $4 \mathrm{~mm}$ in the presence of $4 \mathrm{~mL}$ of the corresponding lubricant sample were made. Coefficient of friction was measured during tests and each lubricant sample was tested at least three times under this test condition. All tests were carried out at room temperature and a relative humidity ranging $20-40 \%$.

In all cases, the specimens used in the tribological tests were ultrasonically cleaned with heptane for 10 min, rinsed in ethanol and dried in hot air.

\subsection{Surface Characterization}

The wear depth on the disc surface was measured after the 60-min tests using a confocal microscope (Leica DCM 3D). Scanning electron microscopy (SEM) and energy dispersive spectroscopy (EDS) were also used in order to study the wear mechanism and the lubricant-surface chemical interactions after the 60-min tests. $20 \mathrm{kV}$ of acceleration voltage was selected to do the SEM-EDS analysis.

XPS analysis through monochromatized Al K-alpha X-ray radiation were developed using a photoelectron spectrometer (SPECS) with a hemispheral energy analyser (type Phoibos). A single survey spectrum with energy pass $90 \mathrm{eV}$ and energy step $1 \mathrm{eV}$ was taken for every sample. Likewise, high-resolution spectra were taken with $30 \mathrm{eV}$ energy pass and $0.1 \mathrm{eV}$ energy step. Signal-to-noise ratio of the element in the sample determined the number of scans for high-resolution spectra.

\section{Results and discussion}




\subsection{Physicochemical properties}

Thermogravimetric analysis (TGA) of some phosphonium cation-based ionic liquids, including the $\left[\mathrm{P}_{6,6,6,14}\right]\left[(\mathrm{iC} 8)_{2} \mathrm{PO}_{2}\right]$ and $\left[\mathrm{P}_{6,6,6,14}\right][\mathrm{BEHP}]$ ones, was previously reported in [13]. Fig. 1 compares TGA curves of both ionic liquids and the base oil (PAO 4) under both oxygen and nitrogen atmospheres. The base oil exhibited similar thermal behavior under both atmospheres. However, a rapid degradation under oxygen atmosphere (more reactive), with the onset of degradation at a temperature of about $240{ }^{\circ} \mathrm{C}$, can be observed. On the other hand, a more gradual degradation, starting at about $247^{\circ} \mathrm{C}$, was observed under an inert (nitrogen) atmosphere.

Both ionic liquids exhibited higher degradation temperatures than the base oil, specially under nitrogen atmosphere where their resistance to the pyrolysis process has great influence. Two steps degradation curve were observed for the $\left[\mathrm{P}_{6,6,6,14}\right]$ [BEHP] IL, probably due to the more reactive phosphate anion type [48].
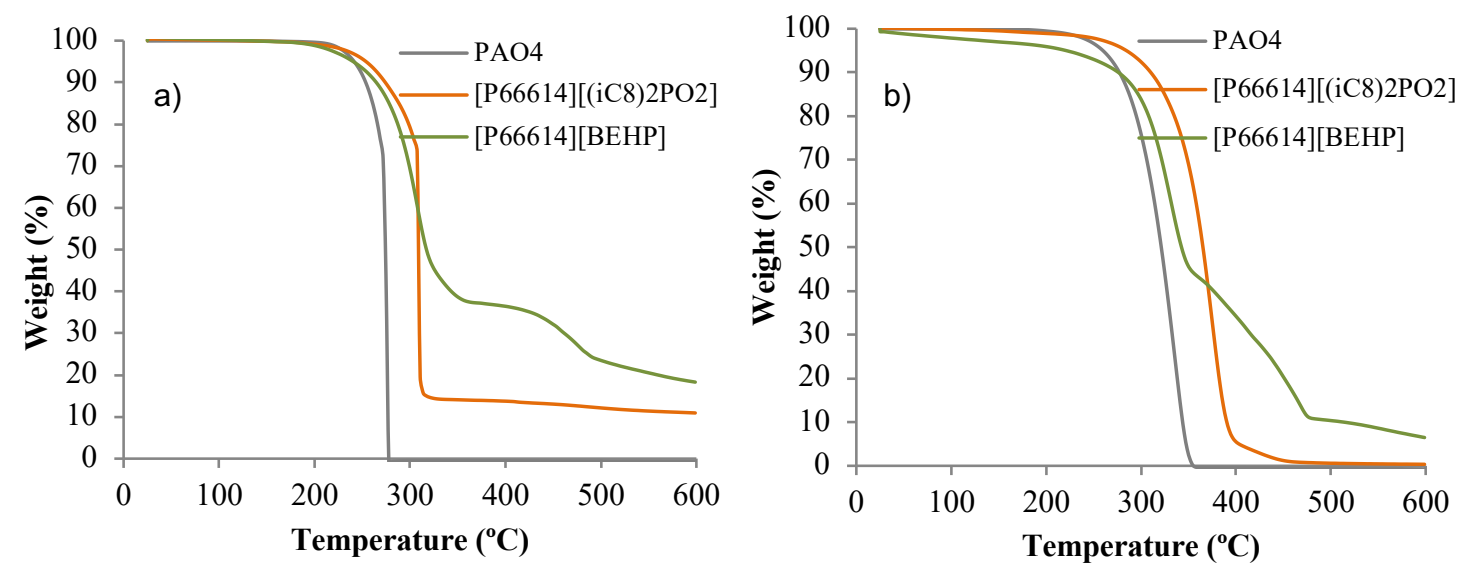

Fig. 1 Thermogravimetric analysis under: (a) $\mathrm{O}_{2}$ atmosphere, (b) $\mathrm{N}_{2}$ atmosphere.

The use of both studied ILs as additive only causes a slight increase in density and viscosity values in comparison with that of the pure base oil. Table 3 shows the viscosity changes with the additive concentration in all cases.

Table 3 Density and viscosity of lubricant samples.

\begin{tabular}{|c|c|c|c|c|c|c|}
\hline \multirow{2}{*}{ Lubricant } & \multirow{2}{*}{$\begin{array}{c}\text { Density }\left(\mathrm{g} / \mathrm{cm}^{3}\right)^{*} \\
20^{\circ} \mathrm{C}\end{array}$} & \multicolumn{5}{|c|}{ Viscosity $\left(\mathrm{mm}^{2} / \mathbf{s}\right)^{*}$} \\
\hline & & $20^{\circ} \mathrm{C}$ & $40^{\circ} \mathrm{C}$ & $60{ }^{\circ} \mathrm{C}$ & $80^{\circ} \mathrm{C}$ & $100{ }^{\circ} \mathrm{C}$ \\
\hline $\mathrm{PAO} 4$ & 0.8153 & 36.802 & 16.891 & 9.244 & 5.723 & 3.892 \\
\hline $\mathrm{PAO} 4+0.5 \%\left[\mathrm{P}_{6,6,6,14}\right]\left[(\mathrm{iC} 8)_{2} \mathrm{PO}_{2}\right]$ & 0.8157 & 37.112 & 17.006 & 9.292 & 5.733 & 3.902 \\
\hline $\mathrm{PAO} 4+1 \%\left[\mathrm{P}_{6,6,6,14}\right]\left[(\mathrm{iC} 8)_{2} \mathrm{PO}_{2}\right]$ & 0.8162 & 37.410 & 17.118 & 9.336 & 5.765 & 3.855 \\
\hline PAO $4+0.5 \%\left[\mathrm{P}_{6,6,6,14}\right][\mathrm{BEHP}]$ & 0.8159 & 37.242 & 17.007 & 9.313 & 5.785 & 3.990 \\
\hline PAO $4+1 \%\left[\mathrm{P}_{6,6,6,14}\right][\mathrm{BEHP}]$ & 0.8162 & 37.413 & 17.168 & 9.320 & 5.746 & 3.893 \\
\hline PAO $4+0.4 \%$ ZDDP & 0.8164 & 36.883 & 16.922 & 9.246 & 5.721 & 3.889 \\
\hline PAO $4+0.8 \%$ ZDDP & 0.8174 & 37.004 & 16.953 & 9.263 & 5.723 & 3.887 \\
\hline
\end{tabular}

* Measured in an SVM 3001 Stabinger Viscometer 


\subsection{Tribological tests}

Both the traction coefficient and ECR versus mean entrainment speed at different temperatures were measured for pure PAO 4 and the mixtures with the maximum phosphorous concentration described in section 2.1. Fig. 2 shows the temperature dependence of the traction coefficient. For all lubricant samples tested, the higher the temperature the lower the traction coefficient in the zone of hydrodynamic lubrication regime due to reduction in the lubricant viscosity and then in the lubricant film thickness. On the other hand, the traction coefficient increased sharply at increasing temperatures in the zone of mixed lubrication regime, where contact between surfaces take place. With regard to the ECR behavior, as expected a decrease in ECR values leads to higher friction due to the increase in the asperities contact in both mixed and boundary lubrication regimes. Test lubricated with PAO $4+1 \%\left[\mathrm{P}_{6,6,6,14}\right][\mathrm{BEHP}]$ exhibits traction coefficient results very similar than those obtained for pure PAO 4. However, the addition of $1 \%$ $\left[\mathrm{P}_{6,6,6,14}\right]\left[(\mathrm{iC} 8)_{2} \mathrm{PO}_{2}\right]$ to the base oil causes the elastohydrodynamic regimen to be reached at higher speeds, especially at the higher temperatures studied. The same behavior can be observed in the tests lubricated with PAO $4+0.8 \%$ ZDDP. 

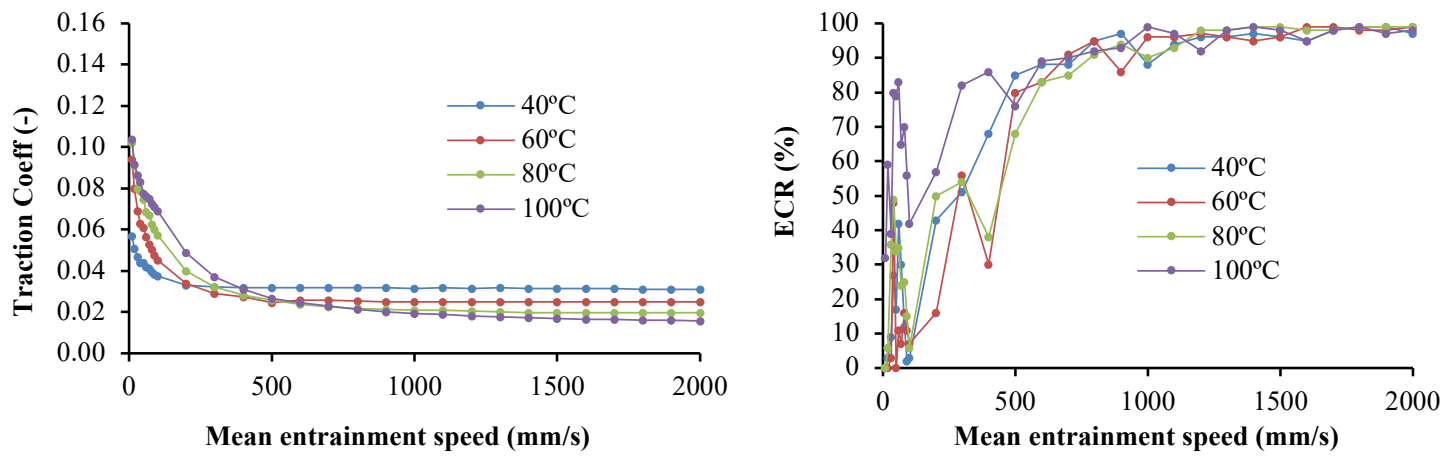

$\mathrm{PAO} 4+1 \%\left[\mathrm{P}_{6,6,6,14}\right]\left[(\mathrm{iC} 8)_{2} \mathrm{PO}_{2}\right]$
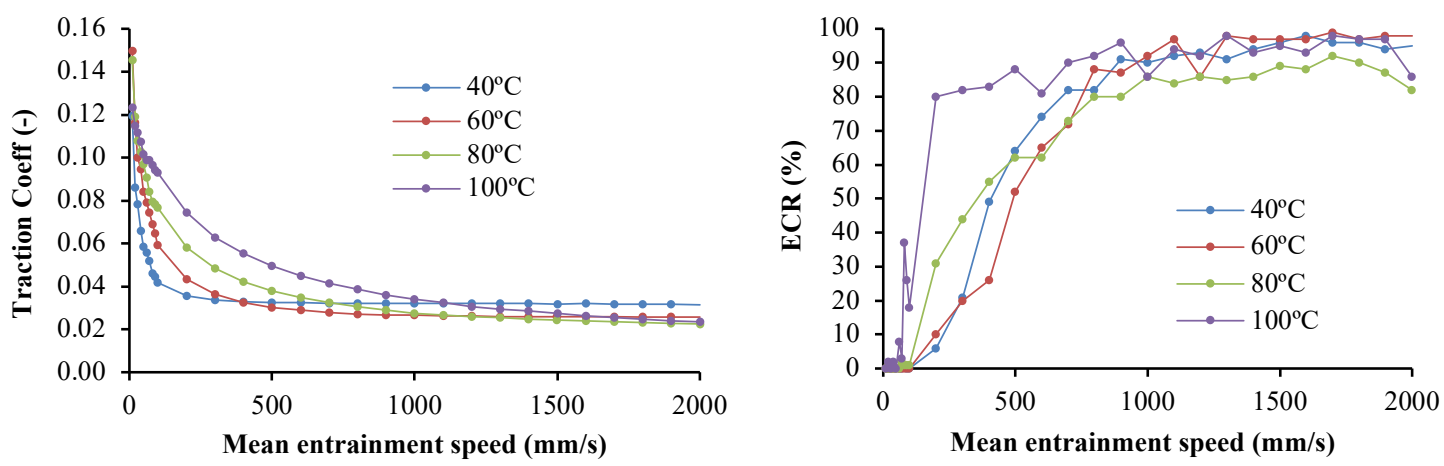

PAO $4+1 \%\left[P_{6,6,6,14}\right][$ BEHP $]$
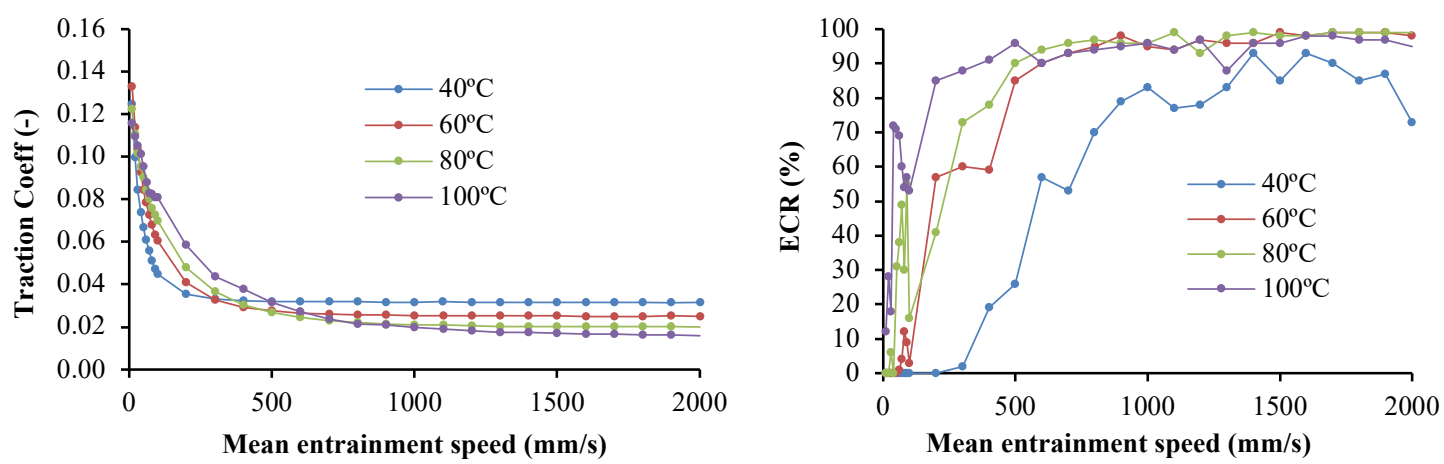

PAO $4+0.8 \%$ ZDDP
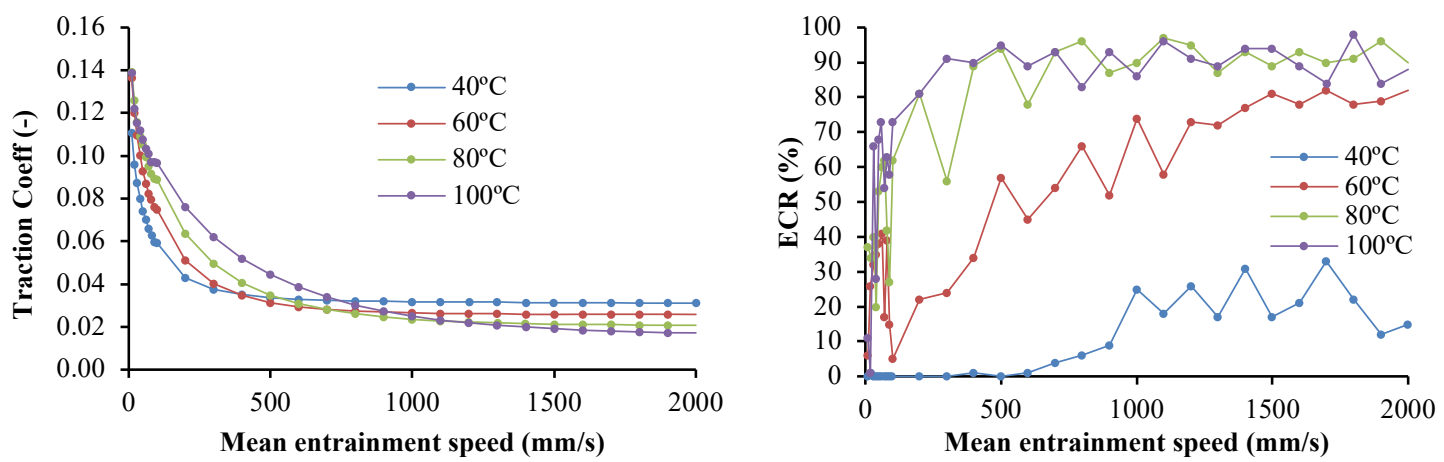

Fig. 2 Traction coefficient (Stribeck curves) and electrical contact resistance (ECR) during tests at different temperatures.

Fig. 3 shows the thickness of the tribofilm formed on the ball for tests made with both ILs compared with the one from the ZDDP-containing mixture. As can be observed, lubricant with $\left[\mathrm{P}_{6,6,6,14}\right]\left[(\mathrm{iC} 8)_{2} \mathrm{PO}_{2}\right]$ as 
additive exhibited a rapid tribofilm formation compared with PAO $4+1 \%\left[\mathrm{P}_{6,6,6,14}\right][\mathrm{BEHP}]$, which showed lower tribofilm thickness values, probably due to a less capacity to interact with the surface. On the other hand, the PAO $4+0.8 \%$ ZDDP mixture showed the biggest final film thickness despite of its lower growing rate in comparison with the mixture of $\mathrm{PAO} 4+\left[\mathrm{P}_{6,6,6,14}\right]\left[(\mathrm{iC} 8)_{2} \mathrm{PO}_{2}\right]$.

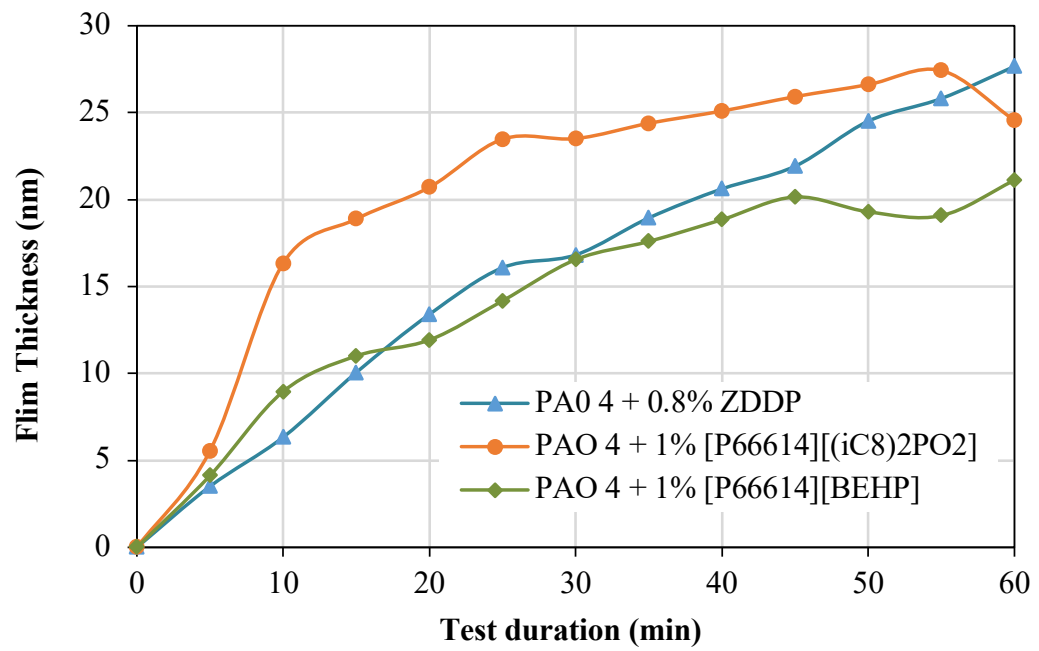

Fig. 3 Tribofilm thickness formed on the ball's surface.

The above-mentioned tribofilm formation results are in concordance with the obtained interference images

(Fig. 4). As can be observed, a color change from blue to brown can be observed at the contact as the tribofilm thickness increases with time. The mixtures containing $\left[\mathrm{P}_{6,6,6,14}\right]\left[(\mathrm{iC} 8)_{2} \mathrm{PO}_{2}\right]$ and ZDDP showed a significant tribofilm build up almost from the test beginning; meanwhile, the $\left[\mathrm{P}_{6,6,6,14}\right][\mathrm{BEHP}]$-containing mixture showed a weaker tribofilm formation.

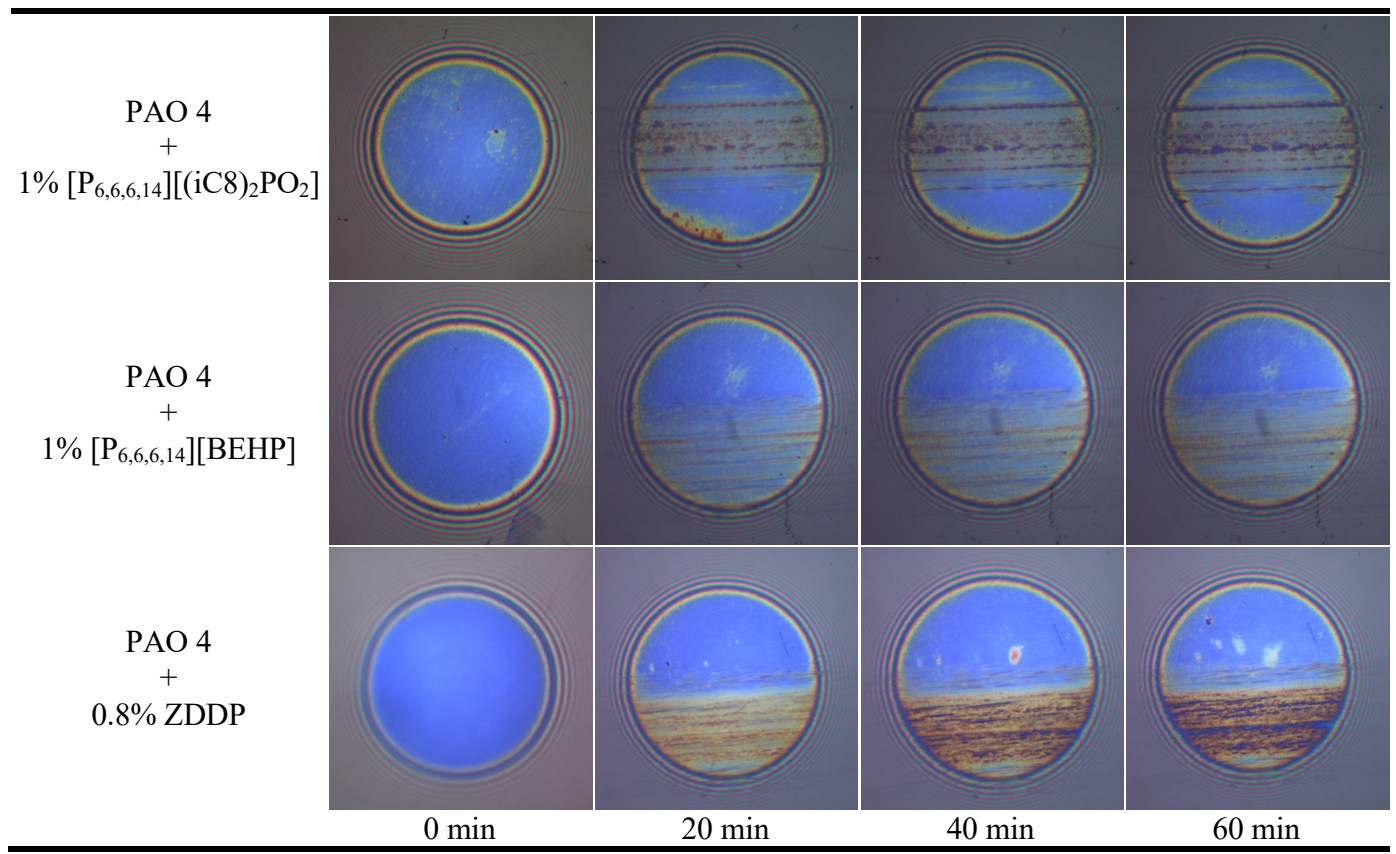

Fig. 4 Interference images of film formation on the ball's surface at 0, 20, 40 and $60 \mathrm{~min}$. 
Fig. 5. shows friction coefficient versus testing time during tests made with the base oil and the mixtures with the lowest concentration of ionic liquids and ZDDP (0.5 and $0.4 \%$ wt., respectively) in the 60 -min tribological tests. As can be observed, all mixtures presented lower friction coefficient than the base oil, but ZDDP-containing blend clearly showed a better behavior. In addition, wear volume measured on the lower specimen after tests is also displayed in Fig. 5. Both ionic liquids led to an important wear reduction compared to the base oil, especially the $\left[\mathrm{P}_{6,6,6,14}\right]\left[(\mathrm{iC} 8)_{2} \mathrm{PO}_{2}\right] \mathrm{IL}$, which reduced wear similarly to ZDDP. This is a remarkable result taking into account the well-known antiwear performance of this traditional antiwear additive.
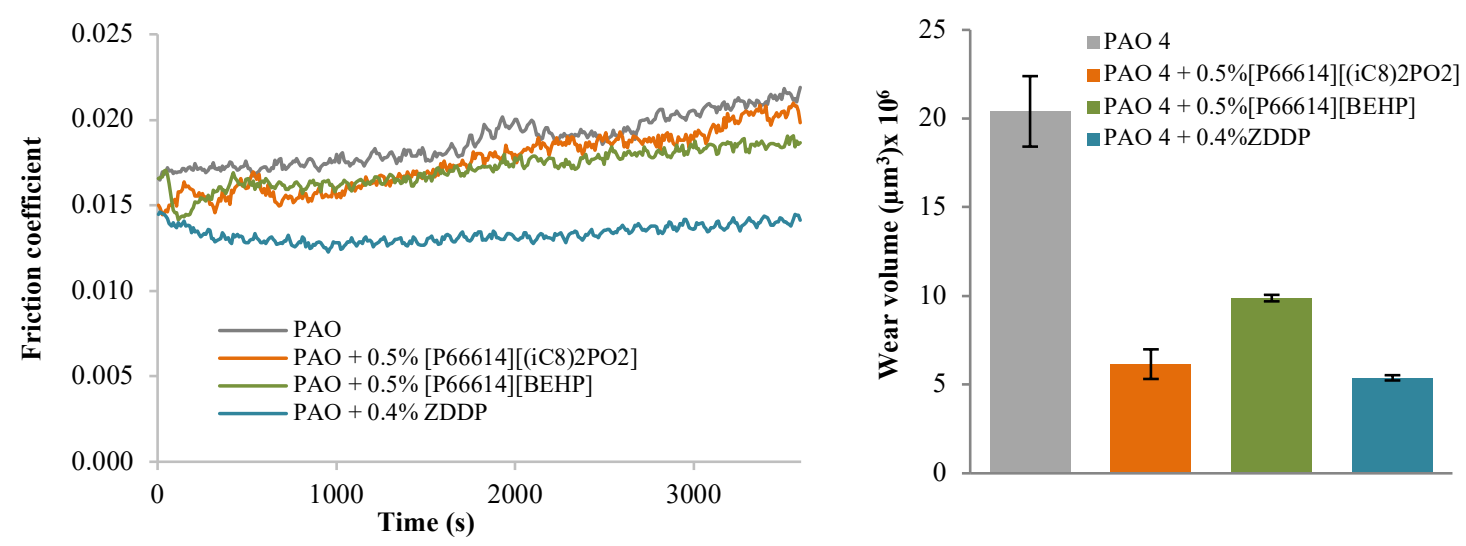

Fig. 5 Friction coefficient and mean wear volume in the 60-min tests lubricated with the base oil and the blends with the lowest concentration.

Friction values recorded in the 60 -min tests made with the highest additive concentration shows that both ILs significantly reduce friction coefficient compared to the neat PAO 4 (Fig. 6) and have similar friction reduction behavior than the mixture containing ZDDP. However, higher ZDDP concentration led to higher friction coefficient, while higher IL concentration led to lower friction coefficient. With regard to the antiwear behavior (Fig. 6), a remarkable wear reduction was observed when $1 \%$ wt. of both ILs was used as additive, showing the $\left[\mathrm{P}_{6,6,6,14}\right]\left[(\mathrm{iC} 8)_{2} \mathrm{PO}_{2}\right]$ IL the lowest wear values, close to the ones of the mixture containing $0.8 \%$ wt. of ZDDP. The above tribological behavior agree with previous results obtained for both ILs used as additive to a mineral oil, where the $\left[\mathrm{P}_{6,6,6,14}\right]\left[(\mathrm{iC} 8)_{2} \mathrm{PO}_{2}\right]$ ionic liquid exhibited the best tribological behavior [42]. 

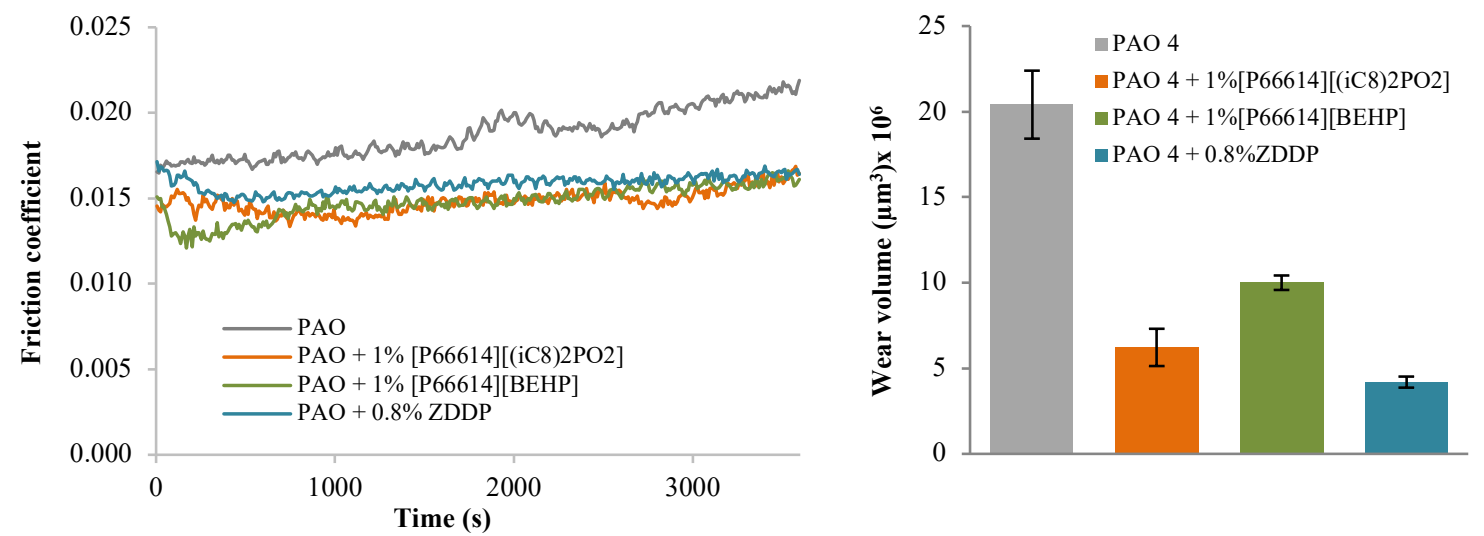

Fig. 6 Friction coefficient and mean wear volume in the 60-min tests lubricated with the base oil and the blends with de highest concentrations.

\subsection{Surface characterization}

Worn surfaces of the 60-min tests were examined by using SEM/EDS and confocal microscopy. Fig. 7 shows SEM images and waviness and roughness of a transversal profile of the wear scar after tests lubricated with pure $\mathrm{PAO} 4$ and all the blends containing $\left[\mathrm{P}_{6,6,6,14}\right]\left[(\mathrm{iC} 8)_{2} \mathrm{PO}_{2}\right],\left[\mathrm{P}_{6,6,6,14}\right][\mathrm{BEHP}]$ and $\mathrm{ZDDP}$. SEM images showed evidence of plastic deformation in all the worn surfaces, with a deep well-defined scar with high roughness $(\mathrm{Ra} \approx 3 \mu \mathrm{m})$ and a predominant adhesive wear as a result of the tests lubricated with pure PAO 4 (Fig. 6a). The use of both ILs as additives provoked less surface damage (Figs. 6b, 6c, 6d and 6e) with a smaller wear scar and a roughness below $1.9 \mu \mathrm{m} \mathrm{Ra}$ in all cases, especially when $\left[\mathrm{P}_{6,6,6,14}\right]\left[(\mathrm{iC} 8)_{2} \mathrm{PO}_{2}\right] \mathrm{IL}$ was employed (Fig. $6 \mathrm{~b}$ and $\left.6 \mathrm{c}\right)$. However, grooves in the sliding direction can be observed in the wear surface lubricated with IL-containing mixtures, which indicates abrasive wear.
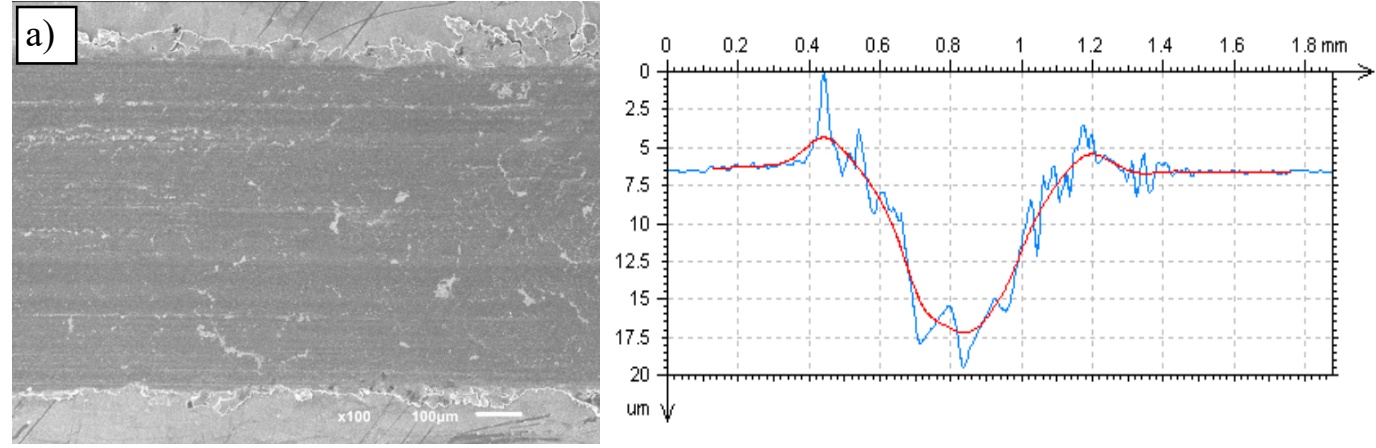

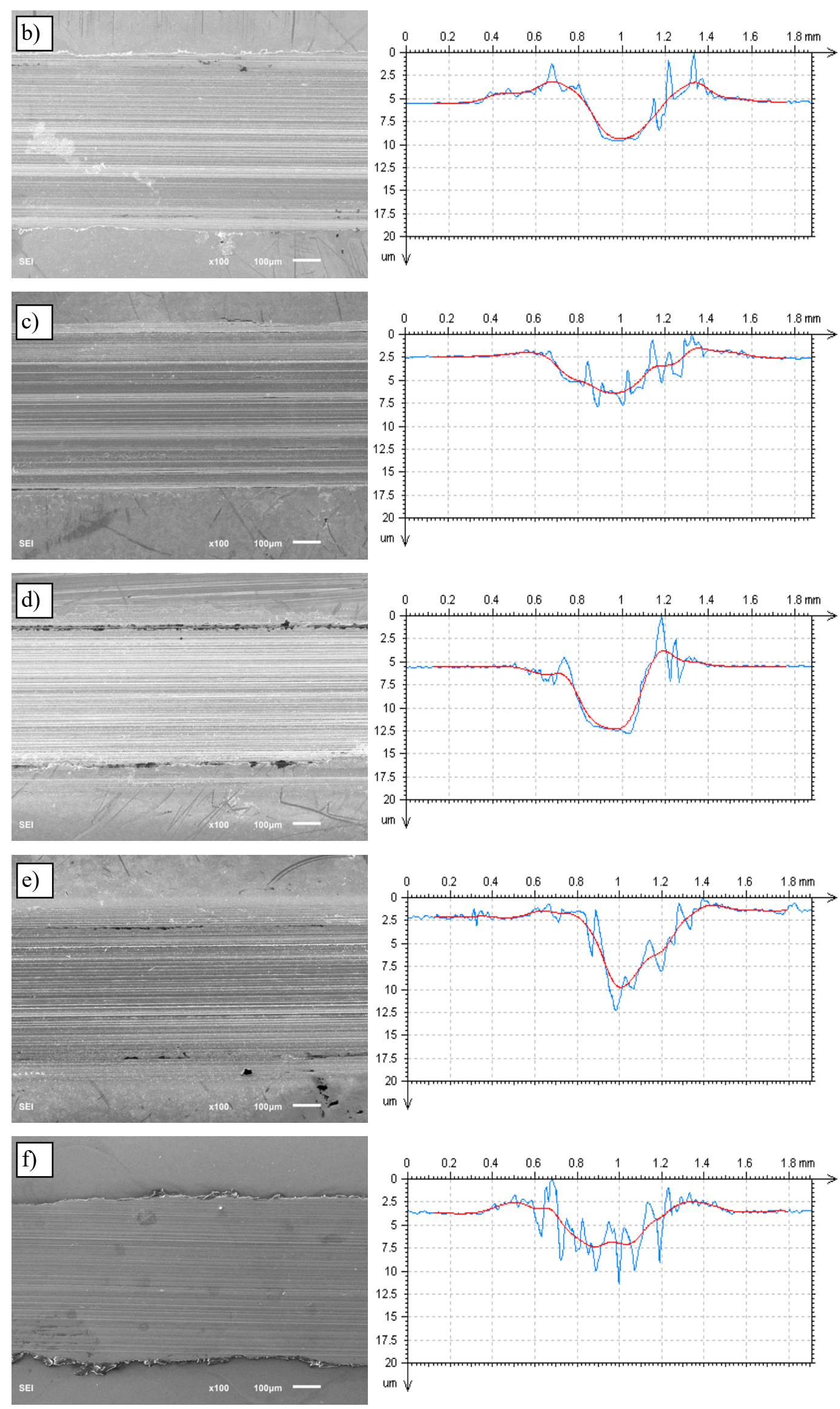

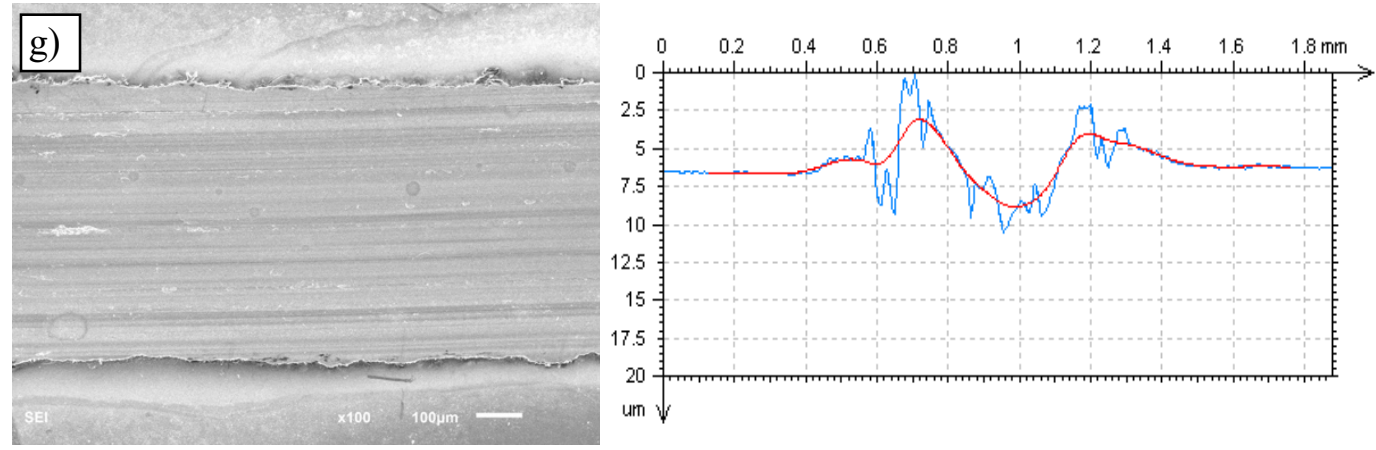

Fig. 7 Worn surfaces: SEM images and waviness and roughness of a transversal profile from tests with: (a) neat PAO 4, (b) PAO $4+0.5 \%\left[\mathrm{P}_{6,6,6,14}\right]\left[(\mathrm{iC} 8)_{2} \mathrm{PO}_{2}\right]$, (c) $\mathrm{PAO} 4+1 \%\left[\mathrm{P}_{6,6,6,14}\right]\left[(\mathrm{iC} 8)_{2} \mathrm{PO}_{2}\right]$,

(d) $\mathrm{PAO} 4+0.5 \%\left[\mathrm{P}_{6,6,6,14}\right][\mathrm{BEHP}]$, (e) $\mathrm{PAO} 4+1 \%\left[\mathrm{P}_{6,6,6,14}\right][\mathrm{BEHP}]$, (f) $\mathrm{PAO} 4+0.4 \% \mathrm{ZDDP}$, (g) PAO $4+0.8 \%$ ZDDP.

The EDS spectra (Table 5) showed that for the PAO 4 and the ionic liquid samples the chemical elements found on the worn surface were those present in the steel, while phosphorus, sulphur and zinc were only detected for mixtures with ZDDP.

Table 5 Results obtained from EDS analysis after 60-min tribological tests.

\begin{tabular}{|c|c|c|c|c|c|c|c|}
\hline Sample & $\begin{array}{c}\text { C } \\
\text { (\% wt.) }\end{array}$ & $\begin{array}{c}\text { O } \\
\text { (\% wt.) }\end{array}$ & $\begin{array}{c}\text { P } \\
\text { (\% wt.) }\end{array}$ & $\begin{array}{c}\text { S } \\
\text { (\% wt.) }\end{array}$ & $\begin{array}{c}\text { Zn } \\
\text { (\% wt.) }\end{array}$ & $\begin{array}{c}\mathrm{Cr} \\
\text { (\% wt.) }\end{array}$ & $\begin{array}{c}\text { Fe } \\
\text { (\% wt.) }\end{array}$ \\
\hline PAO 4 & 8.43 & 11.52 & - & - & - & 2.68 & 77.37 \\
\hline $\begin{array}{l}\mathrm{PAO} 4+0.5 \% \\
{\left[\mathrm{P}_{6,6,6,14}\right]\left[(\mathrm{iC} 8)_{2} \mathrm{PO}_{2}\right]}\end{array}$ & 8.44 & 9.88 & - & - & - & 2.39 & 79.29 \\
\hline $\mathrm{PAO} 4+1 \%\left[\mathrm{P}_{6,6,6,14}\right]\left[(\mathrm{iC} 8)_{2} \mathrm{PO}_{2}\right]$ & 7.15 & 9.30 & - & - & - & 2.10 & 81.45 \\
\hline PAO $4+0.5 \%\left[\mathrm{P}_{6,6,6,14}\right][\mathrm{BEHP}]$ & 6.15 & 14.65 & & & & 1.74 & 76.40 \\
\hline PAO $4+1 \%\left[\mathrm{P}_{6,6,6,14}\right][\mathrm{BEHP}]$ & 6.24 & 9.43 & - & - & - & 2.00 & 82.34 \\
\hline $\mathrm{PAO} 4+0.4 \% \mathrm{ZDDP}$ & 8.38 & 6.16 & 0.66 & 1.71 & 1.20 & 2.35 & 79.54 \\
\hline PAO $4+0.8 \%$ ZDDP & 5.52 & 7.29 & 0.78 & 1.85 & 1.40 & 2.20 & 80.96 \\
\hline
\end{tabular}

From XPS analysis, Fe2p3/2 was fitted using three different curves described as Gaussian-lorentzian product 70:30 with the same fwhm value. However, and according to the work of Mangolini and Mayer $[49,50]$, curve centered around $707.5 \mathrm{eV}$ and assignable as $\mathrm{Fe}(0)$, was modified with an exponential blend with $\mathrm{k}=0.65$; curve centered around $711.0 \mathrm{eV}$ and assignable to $\mathrm{Fe}(\mathrm{III})$, was modified with an exponential blend with $\mathrm{k}=1.5$; curves centered around $713.0 \mathrm{eV}$ is assumed to be FeOOH. Fig. 8 shows that samples containing $\left[\mathrm{P}_{6,6,6,14}\right]\left[(\mathrm{iC} 8)_{2} \mathrm{PO}_{2}\right]$ or $\left[\mathrm{P}_{6,6,6,14}\right][\mathrm{BEHP}]$ have a higher amount of $\mathrm{Fe}(\mathrm{III})$ and a lower amount of $\mathrm{Fe}(0)$ than samples with ZDDP or neat base oil. Furthermore, the Fe(III) is higher in samples lubricated with $\left[\mathrm{P}_{6,6,6,14}\right][\mathrm{BEHP}]$ which, in fact, turned out to be the less effective lubricant. Samples lubricated with $\left[\mathrm{P}_{6,6,6,14}\right]\left[(\mathrm{iC} 8)_{2} \mathrm{PO}_{2}\right]$ shows also a higher amount of $\mathrm{Fe}(\mathrm{III})$ than the other samples, but it is much closer to ZDDP or PAO than $\left[\mathrm{P}_{6,6,6,14}\right][\mathrm{BEHP}]$. This agrees with the tribological properties of $\left[\mathrm{P}_{6,6,6,14}\right]\left[(\mathrm{iC} 8)_{2} \mathrm{PO}_{2}\right]$, working better than $\left[\mathrm{P}_{6,6,6,14}\right][\mathrm{BEHP}]$ and similarly to ZDDP. 


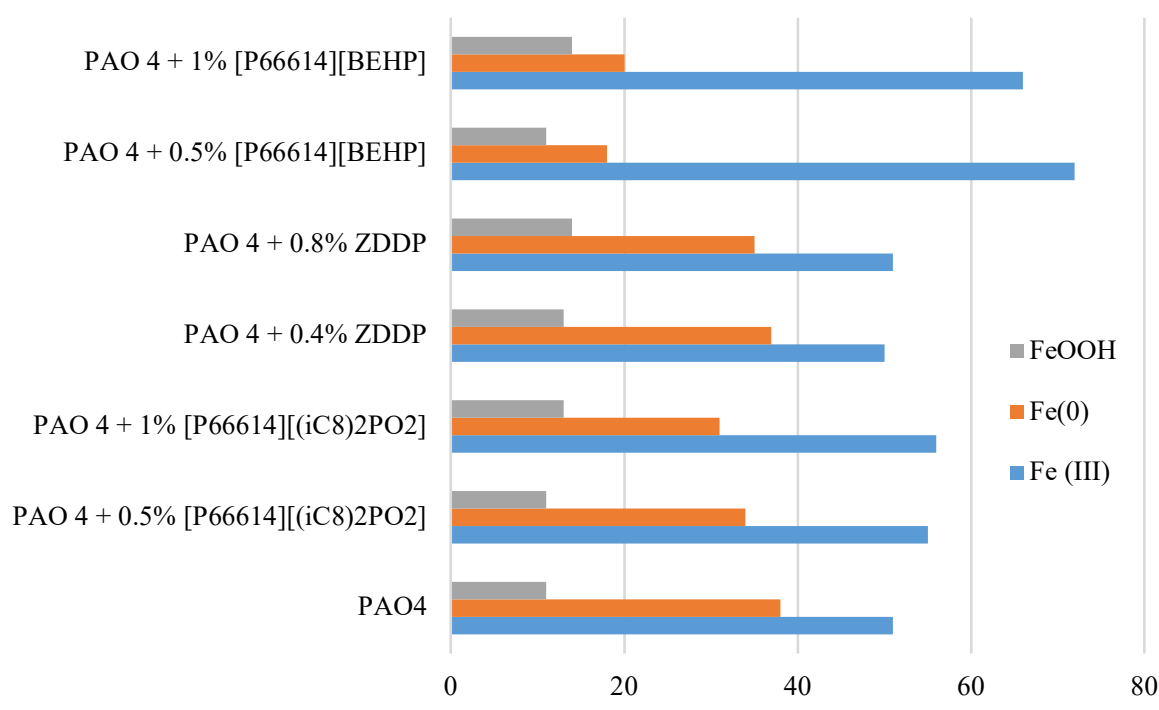

Fig. 8 Relative content in iron.

However, ZDDP samples show the presence of $\mathrm{Zn}$ with a $\mathrm{Zn} 2 \mathrm{p} 3 / 2$ peak at about $1023 \mathrm{eV}$, which is commonly assigned to $\mathrm{ZnO}[42,51]$. Furthermore, despite of the fact that the ionic liquid contains phosphorus, two P2p doublets can be detected in samples with ZDDP (Fig. 9), the first one at 134.0 and $135.0 \mathrm{eV}$ and the second one at 140.5 and $141.5 \mathrm{eV}$, whereas only one appears in the samples with $\left[\mathrm{P}_{6,6,6,14}\right]\left[(\mathrm{iC} 8)_{2} \mathrm{PO}_{2}\right]$ at 133.9 and $134.9 \mathrm{eV}$ (Fig. 10) or $\left[\mathrm{P}_{6,6,6,14}\right][\mathrm{BEHP}]$ at 133.8 and $135.0 \mathrm{eV}$ (Fig. 11). The common doublet (at 134 and $135 \mathrm{eV}$ ) can be interpreted as the presence of phosphates [52], whereas the highest one is usually detected in samples containing ZDDP [53].

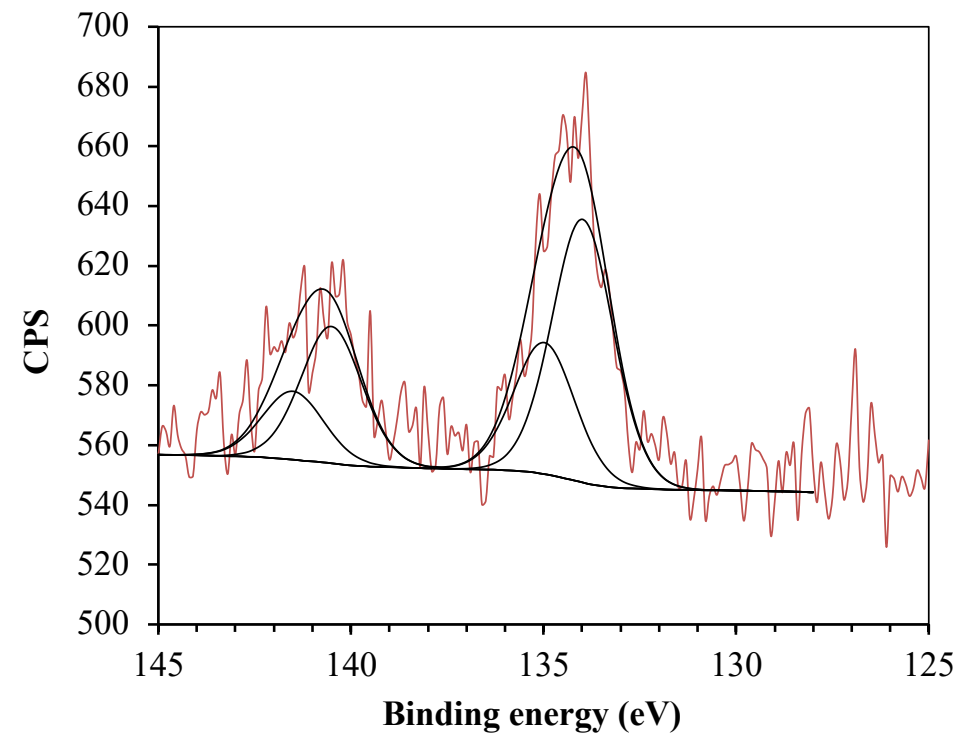

Fig. 9 XPS P2p spectrum for PAO $4+0.4 \%$ ZDDP sample. 


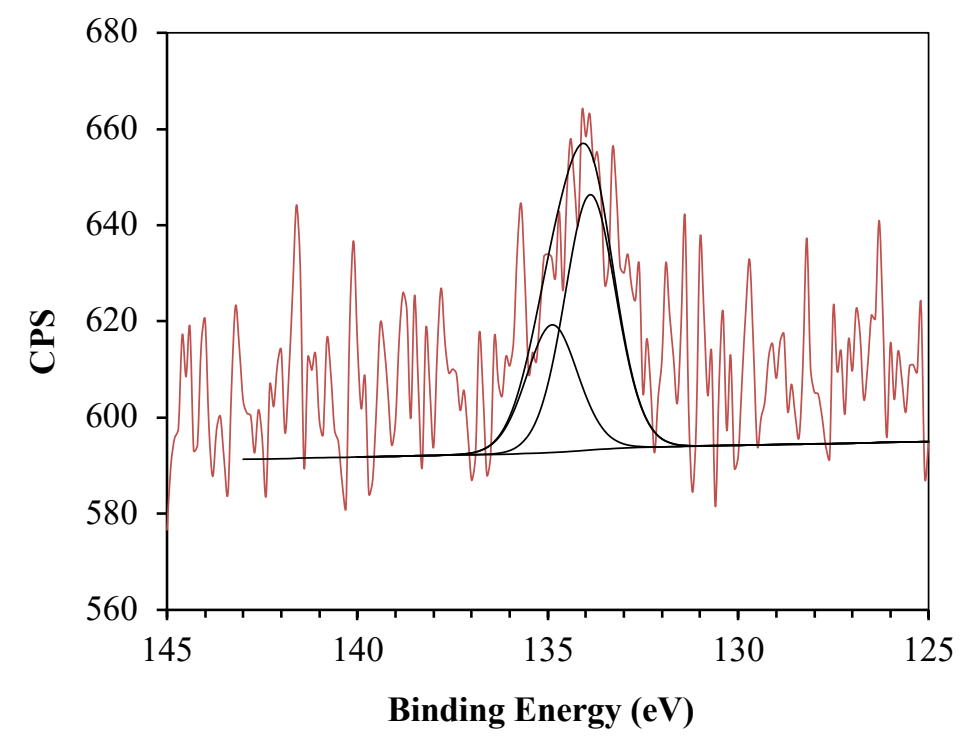

Fig. 10 XPS P2p spectrum for PAO $4+0.5 \%\left[\mathrm{P}_{6,6,6,14}\right]\left[(\mathrm{iC} 8)_{2} \mathrm{PO}_{2}\right]$ sample.

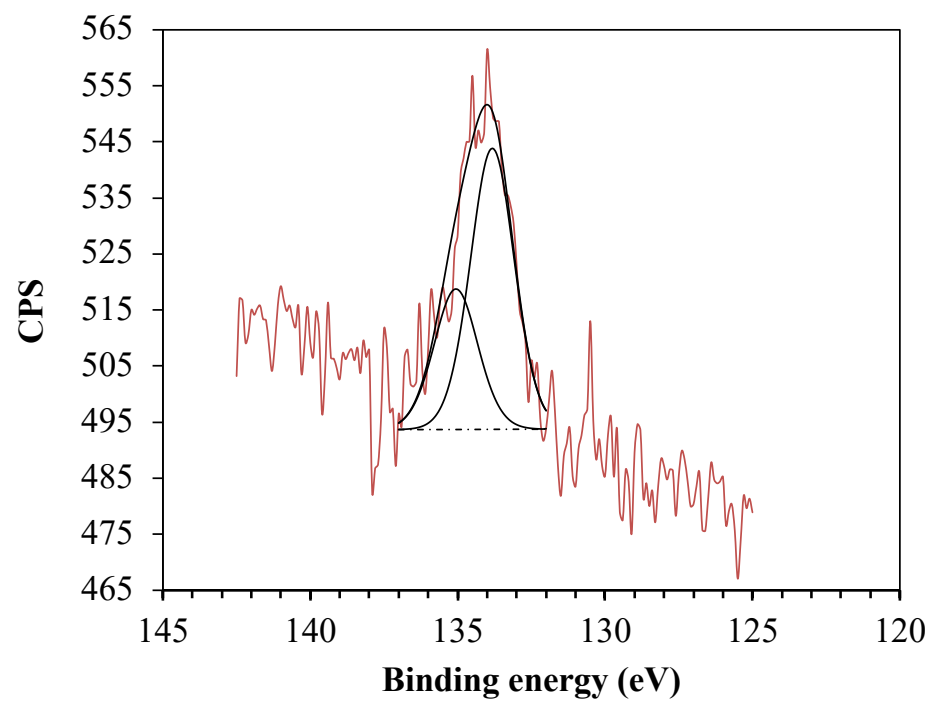

Fig. 11 XPS P2p spectrum for PAO $4+0.5 \%\left[\mathrm{P}_{6,6,6,14}\right][\mathrm{BEHP}]$ sample. 


\section{Conclusions}

The traction behavior, tribofilm formation, friction and wear behavior of the trihexyltetradecylphosphonium bis(2,4,4-trimethylpentyl) phosphinate $\left(\left[\mathrm{P}_{6,6,6,14}\right]\left[(\mathrm{iC} 8)_{2} \mathrm{PO}_{2}\right]\right)$ and trihexyltetradecylphosphonium bis(2-ethylhexyl) phosphate $\left(\left[\mathrm{P}_{6,6,6,14}\right][\mathrm{BEHP}]\right)$ phosphonium cation-based ionic liquids, used as lubricant additive to a polyalphaolefin (PAO 4), were studied. Two mixtures containing zinc dialkyldithiophosphate (ZDDP), with similar phosphorous concentration to that of the ILcontaining mixtures, were used as comparison samples. The following main conclusions can be drawn from this work:

- The thermogravimetric analysis showed that the $\left[\mathrm{P}_{6,6,6,14}\right]\left[(\mathrm{iC} 8)_{2} \mathrm{PO}_{2}\right]$ and $\left[\mathrm{P}_{6,6,6,14}\right][\mathrm{BEHP}]$ ionic liquids have higher degradation temperatures than pure PAO 4.

- The use of both liquids as an additive to the base oil did not increase density and viscosity, so the tribological behavior could be attributed to the adsorption of the ionic liquid on the surface.

- The mixture containing $\left[\mathrm{P}_{6,6,6,14}\right][\mathrm{BEHP}]$ showed similar traction behavior than pure PAO 4; however, the $\left[\mathrm{P}_{6,6,6,14}\right]\left[(\mathrm{iC} 8)_{2} \mathrm{PO}_{2}\right]$ had a similar behavior than the ZDDP-containing mixture.

- $\mathrm{PAO} 4+\left[\mathrm{P}_{6,6,6,14}\right]\left[(\mathrm{iC} 8)_{2} \mathrm{PO}_{2}\right]$ lubricant seems to be more reactive than the blend with $\left[\mathrm{P}_{6,6,6,14}\right][\mathrm{BEHP}]$, exhibiting a faster tribofilm formation, with a similar final thickness to that registered for the ZDDP-containing mixture.

- The 60-min tests showed that the use of the mixtures with IL resulted in lower coefficient of friction than that of the base oil, especially at the maximum IL concentration studied, when similar values to that of the ZDDP were obtained.

- The IL-containing mixtures showed significant wear reduction properties compared to that of the pure base oil, being the mixture with $\left[\mathrm{P}_{6,6,6,14}\right]\left[(\mathrm{iC} 8)_{2} \mathrm{PO}_{2}\right]$ the one that showed the biggest wear reduction. This result agrees with the results of the traction coefficient and tribofilm thickness tests.

- Wear mechanisms observed in the wear scar were adhesive wear and plastic deformation in the test lubricated with pure base oil (PAO 4) and abrasive wear in the tests lubricated with the ILcontaining mixtures. 
- After friction and wear tests, the EDS analysis only found the chemical elements of the steel in the wear scar when pure base oil and the Il-containing mixtures were used as lubricant, while Phosphorous, Sulphur and Zinc were found for the ZDDP-containing mixture.

- The use of the ionic liquids and ZDDP as additive leads to forming phosphates on the wear scar, but the ZDDP also acts via $\mathrm{Zn}$ incorporation.

\section{Acknowledgments}

The authors want to thank to the Spanish Ministry of Economy and Competitiveness and the Foundation for the Promotion in Asturias of the Applied Scientific Research and Technology (FICYT) for supporting the FAILs_LUBEs (DPI2016-79690-R) and LuSuTec (IDI/2018/000131) research projects, respectively.

\section{References}

[1] L. Zhang, D. Feng, B. Xu, Tribological characteristics of alkylimidazolium diethyl phosphates ionic liquids as lubricants for steel-steel contact, Tribol. Lett. 34 (2009) 95-101. doi:10.1007/s11249-009-9412-z.

[2] M. Cai, R. Guo, F. Zhou, W. Liu, Lubricating a bright future: Lubrication contribution to energy saving and low carbon emission, Sci. China Technol. Sci. 56 (2013). doi:10.1007/s11431-0135403-2.

[3] F. Zhou, Y. Liang, W. Liu, Ionic liquid lubricants: Designed chemistry for engineering applications, Chem. Soc. Rev. 38 (2009). doi:10.1039/b817899m.

[4] Z. Tang, S. Li, A review of recent developments of friction modifiers for liquid lubricants (2007present), Curr. Opin. Solid State Mater. Sci. 18 (2014). doi:10.1016/j.cossms.2014.02.002.

[5] M. Petkovic, K.R. Seddon, L.P.N. Rebelo, C. Silva Pereira, Ionic liquids: A pathway to environmental acceptability, Chem. Soc. Rev. 40 (2011). doi:10.1039/c004968a.

[6] K.J. Fraser, D.R. MacFarlane, Phosphonium-based ionic liquids: An overview, Aust. J. Chem. 62 (2009). doi:10.1071/CH08558.

[7] C. Ye, W. Liu, Y. Chen, L. Yu, Room-temperature ionic liquids: A novel versatile lubricant, Chem. Commun. 21 (2001). doi:10.1039/b106935g.

[8] M. Palacio, B. Bhushan, A review of ionic liquids for green molecular lubrication in nanotechnology, Tribol. Lett. 40 (2010). doi:10.1007/s11249-010-9671-8. 
[9] J. Van Rensselar, Cover story: Unleashing the potential of ionic liquids, Tribol. Lubr. Technol. 66 (2010).

[10] A.E. Somers, P.C. Howlett, D.R. Macfarlane, M. Forsyth, A Review of Ionic Liquid Lubricants, Lubricants. 1 (2013) 3-21. doi:10.3390/lubricants1010003.

[11] I. Minami, Ionic liquids in tribology., Molecules. 14 (2009). doi:10.3390/molecules14062286.

[12] M.-D. Bermúdez, A.-E. Jiménez, J. Sanes, F.J. Carrión, Ionic liquids as advanced lubricant fluids, Molecules. 14 (2009). doi:10.3390/molecules14082888.

[13] A. Hernández Battez, M. Bartolomé, D. Blanco, J.L. Viesca, A. Fernández-González, R. González, Phosphonium cation-based ionic liquids as neat lubricants: Physicochemical and tribological performance, Tribol. Int. 95 (2016) 118-131. doi:10.1016/j.triboint.2015.11.015.

[14] A. Hernández Battez, D. Blanco, A. Fernández-González, M.T. Mallada, R. González, J.L. Viesca, Friction, wear and tribofilm formation with a $[\mathrm{NTf}<\inf >2</ \inf >]$ anion-based ionic liquid as neat lubricant, Tribol. Int. 103 (2016). doi:10.1016/j.triboint.2016.06.038.

[15] R. González, A. Hernández Battez, D. Blanco, J.L. Viesca, A. Fernández-González, Lubrication of TiN, CrN and DLC PVD coatings with 1-butyl-1- methylpyrrolidinium tris(pentafluoroethyl)trifluorophosphate, Tribol. Lett. 40 (2010). doi:10.1007/s11249-010-9674-5.

[16] A. García, R. González, A. Hernández Battez, J.L. Viesca, R. Monge, A. Fernández-González, M. Hadfield, Ionic liquids as a neat lubricant applied to steel-steel contacts, Tribol. Int. 72 (2014). doi:10.1016/j.triboint.2013.12.007.

[17] C. Gabler, N. Dörr, G. Allmaier, Influence of cationic moieties on the tribolayer constitution shown for bis(trifluoromethylsulfonyl)imide based ionic liquids studied by $\mathrm{X}$-ray photoelectron spectroscopy, Tribol. Int. 80 (2014). doi:10.1016/j.triboint.2014.06.018.

[18] Y. Zhou, J. Qu, Ionic liquids as lubricant additives: A review, ACS Appl. Mater. Interfaces. 9 (2017). doi:10.1021/acsami.6b12489.

[19] I. Otero, E.R. López, M. Reichelt, M. Villanueva, J. Salgado, J. Fernández, Ionic liquids based on phosphonium cations As neat lubricants or lubricant additives for a steel/steel contact, ACS Appl. Mater. Interfaces. 6 (2014). doi:10.1021/am502980m.

[20] V. Pejakovic̈, M. Kronberger, M. Kalin, Influence of temperature on tribological behaviour of ionic liquids as lubricants and lubricant additives, Lubr. Sci. 26 (2014). doi:10.1002/1s.1233.

[21] A.E. Somers, S.M. Biddulph, P.C. Howlett, J. Sun, D.R. MacFarlane, M. Forsyth, A comparison 
of phosphorus and fluorine containing IL lubricants for steel on aluminium, Phys. Chem. Chem. Phys. 14 (2012). doi:10.1039/c2cp40736a.

[22] W. Liu, C. Ye, Q. Gong, H. Wang, P. Wang, Tribological performance of room-temperature ionic liquids as lubricant, Tribol. Lett. 13 (2002). doi:10.1023/A:1020148514877.

[23] A.E. Jiménez, M.D. Bermúdez, P. Iglesias, F.J. Carrión, G. Martínez-Nicolás, 1-N-alkyl -3methylimidazolium ionic liquids as neat lubricants and lubricant additives in steel-aluminium contacts, Wear. 260 (2006). doi:10.1016/j.wear.2005.04.016.

[24] J. Qu, J.J. Truhan, S. Dai, H. Luo, P.J. Blau, Ionic liquids with ammonium cations as lubricants or additives, Tribol. Lett. 22 (2006). doi:10.1007/s11249-006-9081-0.

[25] W.C. Barnhill, H. Luo, H.M. Meyer, C. Ma, M. Chi, B.L. Papke, J. Qu, Tertiary and Quaternary Ammonium-Phosphate Ionic Liquids as Lubricant Additives, Tribol. Lett. 63 (2016). doi:10.1007/s11249-016-0707-6.

[26] A. Schneider, J. Brenner, C. Tomastik, F. Franek, Capacity of selected ionic liquids as alternative EP/AW additive, Lubr. Sci. 22 (2010). doi:10.1002/1s.120.

[27] A.H. Battez, R. González, J.L. Viesca, D. Blanco, E. Asedegbega, A. Osorio, Tribological behaviour of two imidazolium ionic liquids as lubricant additives for steel/steel contacts, Wear. 266 (2009). doi:10.1016/j.wear.2009.03.043.

[28] K. Mistry, M.F. Fox, M. Priest, Lubrication of an electroplated nickel matrix silicon carbide coated eutectic aluminium-silicon alloy automotive cylinder bore with an ionic liquid as a lubricant additive, Proc. Inst. Mech. Eng. Part J J. Eng. Tribol. 223 (2009). doi:10.1243/13506501JET562.

[29] A.E. Somers, B. Khemchandani, P.C. Howlett, J. Sun, D.R. Macfarlane, M. Forsyth, Ionic liquids as antiwear additives in base oils: Influence of structure on miscibility and antiwear performance for steel on aluminum, ACS Appl. Mater. Interfaces. 5 (2013). doi:10.1021/am4037614.

[30] A.-E. Jiménez, M.-D. Bermúdez, Ionic liquids as lubricants for steel-aluminum contacts at low and elevated temperatures, Tribol. Lett. 26 (2007). doi:10.1007/s11249-006-9182-9.

[31] A.-E. Jiménez, M.-D. Bermúdez, Imidazolium ionic liquids as additives of the synthetic ester propylene glycol dioleate in aluminium-steel lubrication, Wear. 265 (2008). doi:10.1016/j.wear.2008.01.009.

[32] M. Yao, Y. Liang, Y. Xia, F. Zhou, Bisimidazolium ionic liquids as the high-performance 
antiwear additives in poly(ethylene glycol) for steel-steel contacts, ACS Appl. Mater. Interfaces. 1 (2009). doi:10.1021/am800132z.

[33] M. Cai, Y. Liang, M. Yao, Y. Xia, F. Zhou, W. Liu, Imidazolium ionic liquids as antiwear and antioxidant additive in poly(ethylene glycol) for steel/steel contacts, ACS Appl. Mater. Interfaces. 2 (2010). doi:10.1021/am900847j.

[34] J. Qu, D.G. Bansal, B. Yu, J.Y. Howe, H. Luo, S. Dai, H. Li, P.J. Blau, B.G. Bunting, G. Mordukhovich, D.J. Smolenski, Antiwear performance and mechanism of an oil-miscible ionic liquid as a lubricant additive, ACS Appl. Mater. Interfaces. 4 (2012). doi:10.1021/am201646k.

[35] B. Yu, D.G. Bansal, J. Qu, X. Sun, H. Luo, S. Dai, P.J. Blau, B.G. Bunting, G. Mordukhovich, D.J. Smolenski, Oil-miscible and non-corrosive phosphonium-based ionic liquids as candidate lubricant additives, Wear. 289 (2012). doi:10.1016/j.wear.2012.04.015.

[36] W.C. Barnhill, J. Qu, H. Luo, H.M. Meyer, C. Ma, M. Chi, B.L. Papke, Phosphoniumorganophosphate ionic liquids as lubricant additives: Effects of cation structure on physicochemical and tribological characteristics, ACS Appl. Mater. Interfaces. 6 (2014). doi:10.1021/am506702u.

[37] J. Qu, H. Luo, M. Chi, C. Ma, P.J. Blau, S. Dai, M.B. Viola, Comparison of an oil-miscible ionic liquid and ZDDP as a lubricant anti-wear additive, Tribol. Int. 71 (2014). doi:10.1016/j.triboint.2013.11.010.

[38] Y. Zhou, J. Dyck, T.W. Graham, H. Luo, D.N. Leonard, J. Qu, Ionic liquids composed of phosphonium cations and organophosphate, carboxylate, and sulfonate anions as lubricant antiwear additives, Langmuir. 30 (2014) 13301-13311. doi:10.1021/la5032366.

[39] J. Qu, W.C. Barnhill, H. Luo, H.M. Meyer, D.N. Leonard, A.K. Landauer, B. Kheireddin, H. Gao, B.L. Papke, S. Dai, Synergistic Effects between Phosphonium-Alkylphosphate Ionic Liquids and Zinc Dialkyldithiophosphate (ZDDP) as Lubricant Additives, Adv. Mater. 27 (2015). doi:10.1002/adma.201502037.

[40] V. Totolin, I. Minami, C. Gabler, J. Brenner, N. Dörr, Lubrication mechanism of phosphonium phosphate ionic liquid additive in alkylborane-imidazole complexes, Tribol. Lett. 53 (2014). doi:10.1007/s11249-013-0281-0.

[41] B. Khemchandani, A. Somers, P. Howlett, A.K. Jaiswal, E. Sayanna, M. Forsyth, A biocompatible ionic liquid as an antiwear additive for biodegradable lubricants, Tribol. Int. 77 
(2014). doi:10.1016/j.triboint.2014.04.016.

[42] R. González, M. Bartolomé, D. Blanco, J.L. Viesca, A. Fernández-González, A.H. Battez, Effectiveness of phosphonium cation-based ionic liquids as lubricant additive, Tribol. Int. 98 (2016) 82-93. doi:10.1016/j.triboint.2016.02.016.

[43] G. Guangteng, H.A. Spikes, The control of friction by molecular fractionation of base fluid mixtures at metal surfaces, Tribol. Trans. (1997). doi:10.1080/10402009708983681.

[44] A. Cambiella, J.M. Benito, C. Pazos, J. Coca, A. Hernández, J.E. Fernández, Formulation of emulsifiable cutting fluids and extreme pressure behaviour, J. Mater. Process. Technol. (2007). doi:10.1016/j.jmatprotec.2006.11.014.

[45] J.E. Fernández Rico, A. Hernández Battez, D. García Cuervo, Wear prevention characteristics of binary oil mixtures, Wear. (2002). doi:10.1016/S0043-1648(02)00229-6.

[46] N.P. Plant, F.G. Lubricants, How new engine oil specifications are challenging additive suppliers, (2015).

[47] R. Kapadia, R. Glyde, Y. Wu, In situ observation of phosphorous and non-phosphorous antiwear films using a mini traction machine with spacer layer image mapping, Tribol. Int. 40 (2007) 1667-1679. doi:10.1016/J.TRIBOINT.2007.01.021.

[48] M.D. Green, C. Schreiner, T.E. Long, Thermal, rheological, and ion-transport properties of phosphonium-based ionic liquids, J. Phys. Chem. A. 115 (2011) 13829-13835. doi:10.1021/jp206138b.

[49] F. Mangolini, A. Rossi, N.D. Spencer, Influence of metallic and oxidized iron/steel on the reactivity of triphenyl phosphorothionate in oil solution, Tribol. Int. 44 (2011). doi:10.1016/j.triboint.2010.02.009.

[50] T. Mayer, Black spots on carbon steel after contact to lubricating oil with extreme pressure additives: An XPS study, Appl. Surf. Sci. 179 (2001).

[51] L.S. Dake, D.R. Baer, J.M. Zachara, Auger parameter measurements of zinc compounds relevant to zinc transport in the environment, Surf. Interface Anal. 14 (1989). doi:10.1002/sia.740140115.

[52] M. Repka, N. Dörr, J. Brenner, C. Gabler, C. McAleese, O. Ishigo, M. Koshima, Lubricantsurface interactions of polymer-coated engine journal bearings, Tribol. Int. 109 (2017). doi:10.1016/j.triboint.2017.01.017.

[53] S. Akbari, J. Kovač, M. Kalin, Effect of ZDDP concentration on the thermal film formation on 
steel, hydrogenated non-doped and Si-doped DLC, Appl. Surf. Sci. 383 (2016).

doi:10.1016/j.apsusc.2016.04.182. 